I later submitted the specimen to Dr. R. Howard Mole, Pathologist to Birkenhead and Wirral Children's Hospital; etc., who reports as follows :-

"With regard to section submitted, there is no doubt whatever of its malignancy, and I think the cells are epithelial, of what origin I cannot say. There is abundant evidence of cellular mitosis. There is also some lymphocyte and polymorphonuclear celled infiltration. The tumour is moderately vascular."

Thus, apparently, we would be justified in calling this a case of malignancy of the lacrymal gland, notable for its extremely rapid growth of only 40 days up to the inoperable stage shown in the accompanying two photographs.

\title{
A NOTE ON GONIN'S OPERATION FOR DETACHED RETINA
}

BY

J. HeRbert Fisher

LONDON

WHEN the inflammatory exudate from iritis organizes to form a membranous disc which blocks the pupil aperture the pupil of the eye is said to be " occluded." The obstructing membrane is never so dense as to prevent the filtration through it of aqueous fluid from the posterior to the anterior compartment of the chamber.

Iris bombé results from the formation of an annular posterior synechia, when the pupil is said to be "excluded": in this condition the aqueous secretion, being excluded from the anterior compartment, is retained behind the iris, which becomes bellied forward.

In the light of recent knowledge our former incapacity to deal successfully with a detached retina in which a hole could be recognized appears to have been due to the fact that even if by operative or other measures the subretinal fluid could be drained off it was at once replaced by further fluid which flowed, through the hole, from the vitreous humour. The point essential to secure the very practical success which attends Gonin's operation is said to be the " sealing of the hole" in the retina. The determination of the exact point over the hole at which to puncture the sclerotic and choroid with the cautery is a pre-requisite of success. The term "sealing the hole" suggests that the cautery point is passed through the hole in the retina, sears its margins and thus stimulates the production from the retinal tissue of an inflammatory 
exudate which organizes and "occludes" the hole. That this is the real explanation of the success of the operation seems to me most improbable, for the following reasons :-

(a) The determination of the exact point on the surface of the sclerotic which overlies the retinal hole, in a variable but in all cases different plane, must be a matter of such extreme difficulty as to be almost impossible; only an approximation can be achieved.

(b) The point of cautery having penetrated the sclerotic at the site selected and traversed the choroid and sub-retinal fluid must be so cooled in transit as to be unable to exert any heat stimulus on the retina, even if it should exactly hit off the retinal hole.

(c) The detached retina, an extremely thin epiblastic membrane with a minimum of supporting tissue in its structure, is little likely to produce an inflammatory exudate capable of organizing into a membranous diaphragm for the hole, in response to a thermal or any other stimulus.

(d) Even were such a membrane produced it would presumably be no more impervious to fluid than the iritic membrane which occludes a pupil : free communication for the transference of fluid from the intra- to the sub-retinal space would still exist.

There is then in my opinion no apparent reason in this conception of " sealing the hole" for the success which undoubtedly attends Gonin's operation when it is well performed.

The view which I have formed, purely on theoretical grounds, is as follows :-

Formerly cautery puncture to drain off sub-retinal fluid in cases of detachment of retina usually failed to effect a cure because through a rent in the detached portion of the membrane fluid at once flowed from the degenerate vitreous to replace that which had been withdrawn bv the puncture. When Gonin's operation succeeds it does so because if the site of puncture has been determined with sufficient accuracy the retina falls back into apposition with the choroid, as the sub-retinal fluid drains out, in such a way that the portion in which the hole exists corresponds with the site of puncture; the choroid at this point, responding to the stimulus of the cautery, pours out an inflammatory exudate which organizes and firmly attaches the adjacent part of the retina and in doing so forms, as it were, an annular synechia for the retinal hole. Some sub-retinal fluid, no doubt, remains at first, so that the retina is now bombe towards the vitreous; this residue of sub-retinal fluid will in a short time be carried off bv the lvmphatic and vascular channels of the choroid, until the whole of the detached portion of the retina is re-apposed: the " ring synechia" prevents it being renewed by fluid from the vitreous : the normal bulk is restored to the vitreous, at the same time, by fluid from the ciliary secreting mechanism now that it can no longer run to waste by draining through the retinal 
hole into the sub-retinal space, as it was uninterruptedly doing before the operation was performed.

Gonin's operation, therefore, seems to me to achieve success by " excluding" the hole in the retina, to use the term which we apply to pupillary adhesions, not to "occlusion." In the cured case the position of the retinal hole will correspond with the organized choroidal scar which can be recognized with the ophthalmoscope. It would appear to be necessary to determine as accurately as possible before operating in each case to what part of the choroid the retinal hole will correspond when the sub-retinal fluid flows out, and to puncture with the cautery at this point in the overlying sclerotic; the height of the detachment in the region of the hole will presumably be a factor in determining the spot selected for the puncture; the rather free use of a large cautery would increase the chance of success.

A clear apprehension of the modus operandi of Gonin's operation is desirable, and clear thinking may promote further advance in this method of treatment of detachment of retina, which has already achieved so much success. The expression " sealing the hole" seems inappropriate and misleading : " exclusion of the hole " by ring synechia between retina and choroid is perhaps the phrase which will best convey the state of affairs to the ophthalmic surgeon; in using the term he will not conceive of the annular attachment as merely linear at the extreme margins of the hole; a broader area of the circumference is no doubt adherent to the choroidal scar; the surgeon will not need to be reminded that in the presence of the detachment the direction of the current of fluid is from the intra-ocular to the sub-retinal space.

\section{AN EPIDEMIC OF CONJUNCTIVITIS DUE TO INFECTION WITH BACILLUS FAECALIS ALKALIGENES}

BY

\section{R. H. BALFOUR BARROW}

LONDON

My inability to find any record of this organism as a cause of epidemic conjunctivitis leads me to report this outbreak. The epidemic occurred recently in the training ship " Exmouth" which is a training ship for boys for the Royal Navy and the Merchant Service. The ship, which is under the control of the Iondon County Council, lies at anchor in the Thames off the north bank of the river about 20 miles from London. She is built 